\title{
BENEFITS AND RISKS OF MULTIMODAL TRANSPORT WITH A MAIN FOCUS ON THE EU
}

\author{
Barbora Kotkova \& Martin Hromada
}
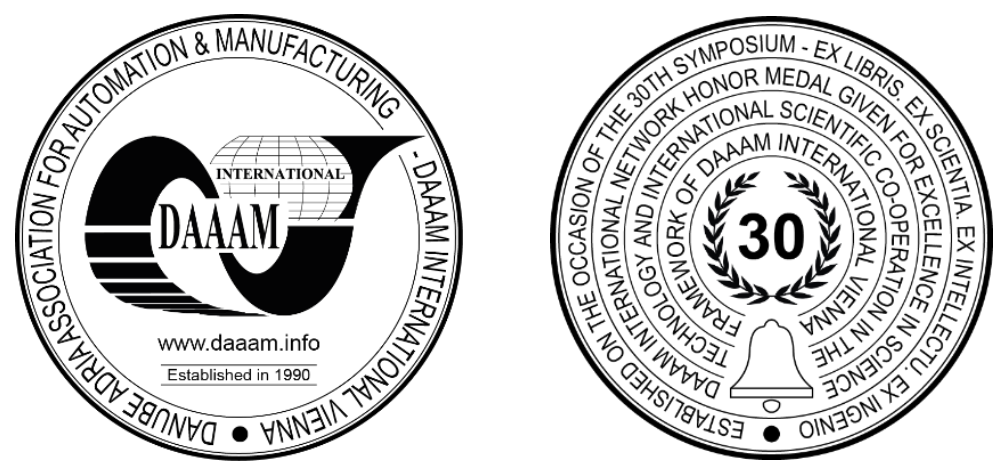

This Publication has to be referred as: Kotkova, B[arbora] \& Hromada, M[artin] (2021). Benefits and Risks of Multimodal Transport with a Main Focus on the EU, Proceedings of the 32nd DAAAM International Symposium, pp.0306-0310, B. Katalinic (Ed.), Published by DAAAM International, ISBN 978-3-902734-33-4, ISSN 1726-9679, Vienna, Austria

DOI: $10.2507 / 32$ nd.daaam.proceedings.044

\begin{abstract}
The article provides an overview of the main benefits and risks of multimodal transport, focusing not only on the European Union. The following is a list of possible measures that can be implemented shortly and those that the states of the Community of the European Union must reach together. Finally, the article presents a model case of the application of multimodal transport and common recommendations leading to the expansion of multimodal transport. The realization of these goals should be common to all states to stop the devastation of the natural environment and improve living conditions.
\end{abstract}

Keywords: environment; risk; safety; transport.

\section{Introduction}

International trade could not exist without a substantial part of it, namely transport. The amount of goods transported is constantly increasing and this trend will continue. It is, therefore, necessary to work now to increase the capacity of individual transport sectors. Part of this task is to improve transport services and speed up transport times. The volumes of passenger and freight transport are constantly increasing, not only within the Czech Republic but also in other European Union countries. The ecological consequences of this development have for a long time been noticeably negatively reflected in human life and the environment. One of the methods that reduce these adverse effects and that can also be applied immediately and effectively is multimodal transport.

Multimodal transport has been defined by the European Conference of Ministers of Transport (ECMT) as transport in which more than two different modes of transport are used to transport goods. The UN Convention on Multimodal Transport is also concluded, concluded in 1981. Multimodal transport is also characterized here as the transport of goods by at least two different modes of transport. For comparison with combined (intermodal) transport, in which the use of the same freight unit is assumed when changing the type of transport, in multimodal transport, there may also be a change in the freight unit, means, or distribution of cargo. In most European countries, road transport predominates in the transport of goods and materials. The total volume of road transport in the European Union decreased from 57,092 million thousand $\mathrm{km}$ in 2007 to 42,588 million thousand $\mathrm{km}$ in 2016. 
However, although the overall indicator for the EU has decreased, this trend does not apply in all countries. In Germany, Spain, France, Portugal, and Poland, for example, there has been an increase. The main reasons for not using multimodal transport to a greater extent are low transport volumes and / or short transport distances. Within Europe, transport distances are indeed very short or there are insufficient and high-quality connections.

It is therefore clear that European countries must actively cooperate in solving the following problems, both in terms of passenger and freight transport:

- Air and road transport is permanently congested. This congestion will increase in the future and the volumes of freight and passenger transport will continue to grow.

- Transport is still $96 \%$ dependent on oil. It has long been known that there will be a clear shortage of oil soon, which is also found in fragile countries.

- Greenhouse gas emissions - global warming is taking place and this trend must be significantly and effectively curtailed

- Transport infrastructure varies significantly within the European Union. In some countries, there are also large differences and shortcomings within a territorial unit.

- Non-European markets are experiencing a boom in transport development and these European markets are ultimately difficult to compete with.

In the Member States of the European Union, road transport predominates in freight transport. The average value of the share of road freight transport in 2016 is $76.4 \%$ of the total volume of transport. Due to the larger share of rail transport, two countries are an exception, namely Latvia. Here, the share of road freight transport is only $23.4 \%$. The second country is Lithuania, where the share of road freight transport in 2016 corresponded to $35.0 \%$, compared to rail, which was $65.0 \%$. For other modes of transport, the Netherlands uses inland waterway transport for freight transport, with a significant share of $44.6 \%$, Romania $29.4 \%$, and Bulgaria $27.2 \%$ in 2016. [1]

It is therefore highly desirable to carry out studies such as this article, collecting and comparing national and community objectives. These can then be used in individual international meetings to pass on the experience that helped to achieve the goal or not. Each database, which is complete and accurate, provides the basis for another professional researcher to eliminate dead ends or, conversely, to develop those that appear to be effective.

\section{Characteristics of basic types of transport and their negative effects}

Transport consists of the following elements: means of transport, transport infrastructure, transport facilities and legislation. [2], [3] The product of transport is transport, which is divided into several types:

- Road transport - it is mainly used for short and medium distances. The advantages include speed and availability, the disadvantage is the high negative burden on the environment and higher accidents.

- Rail transport - is used to transport large volumes, the range is rather medium to long distances and there is a relatively high level of safety. Compared to other modes of transport, electricians have lower energy consumption and emissions.

- Water transport - The high cost of building inland canals does not allow for the necessary expansion, so in the future, it will be more of an effort to maintain and expand the existing ones (applies to the EU).

- Air Transport - It is used primarily for the air transport of passengers, mail, and small parcels. The disadvantage is the high burden on the environment.

- Transport of bicycles and pedestrians - It is mainly used for short transfers, especially in combination with other modes of transport. Both are environmentally friendly, do not cause disturbing noise, and have a positive effect on human health.

\begin{tabular}{|l|r|r|r|r|r|r|r|r|}
\hline \multirow{2}{*}{$\begin{array}{l}\text { Emissions individual } \\
\text { transport modes }\end{array}$} & \multicolumn{7}{|c|}{$\mathbf{2 0 1 9}$} \\
\cline { 2 - 9 } & $\mathrm{CO} 2$ & \multicolumn{1}{c|}{$\mathrm{CO}$} & NOx & N2O & *compound & CH4 & SO2 & particles \\
\hline Transport - total & 21118 & 75974 & 59921 & 705 & 14209 & 949 & 215 & 4400 \\
\hline Individual car transport & 12223 & 62948 & 29050 & 344 & 11146 & 734 & 85 & 2521 \\
\hline Public transport by road & 601 & 768 & 2749 & 12 & 93 & 82 & 3 & 103 \\
\hline Road freight transport & 6693 & 7030 & 20119 & 209 & 942 & 68 & 43 & 1630 \\
\hline Motorbikes & 46 & 2197 & 59 & 1 & 891 & 40 & 0 & 10 \\
\hline Rail transport & 270 & 1657 & 2848 & 103 & 394 & 15 & 2 & 128 \\
\hline Water transport & 10 & 59 & 102 & 0,3 & 14 & 0,9 & 0,1 & 8 \\
\hline Air transport & 1275 & 1314 & 4994 & 36 & 728 & 9 & 82 & 0 \\
\hline
\end{tabular}

*volatile organic compounds

Fig. 1. Overview of the production of emissions of individual modes of transport in 2019 [4] 
The Czech Republic was selected as a reference element for comparing emissions from transport. The results published in the 2019 yearbook by the SYDOS traffic statistics system were used. Total emissions from individual modes of transport for 2019 are shown in Table 1. [4] The largest amount of emissions, taking into account the volume of transport, is produced by air transport. Given that water transport is minimally represented in the Czech Republic and its transport, it appears to be the most environmentally friendly mode of transport in terms of emissions.

\section{Multimodal transport in the EU}

The economic development of the European Union depends to a large extent on the development of transport and related services. The market and its development must be ensured by the existence and support of quality infrastructure across the continent. It is necessary to remove narrow and problematic places of the so-called transport network neck. These are due to the lack of harmonization and fragmentation of Member States' transport infrastructures. The European Union has set up the EU's Common Transport Policy project to eliminate these obstacles. The aim of European transport policy until 2030 is to transfer $30 \%$ of current road freight transport for distances longer than $300 \mathrm{~km}$ in the European Union to rail or waterborne transport. Other priorities of the European Union include reducing greenhouse gases produced by individual transport areas, according to the Commission's so-called White Paper by $60 \%$ by 2050 compared to 1990 . Multimodal transport and its main benefit - reducing the negative impact of road transport on the environment are offered as one of the current possible solutions.

To sufficiently understand the process of implementing multimodal transport, the following table was created by SWOT analysis. It shows the strengths and weaknesses of this transport, the risks, and future opportunities, influencing the development in a positive direction. The assessment of risks related to multimodal transport will vary according to the specific dispositions of the evaluated EU countries. [5], [6].

\begin{tabular}{|c|c|}
\hline Strenghts & Opportunities \\
\hline 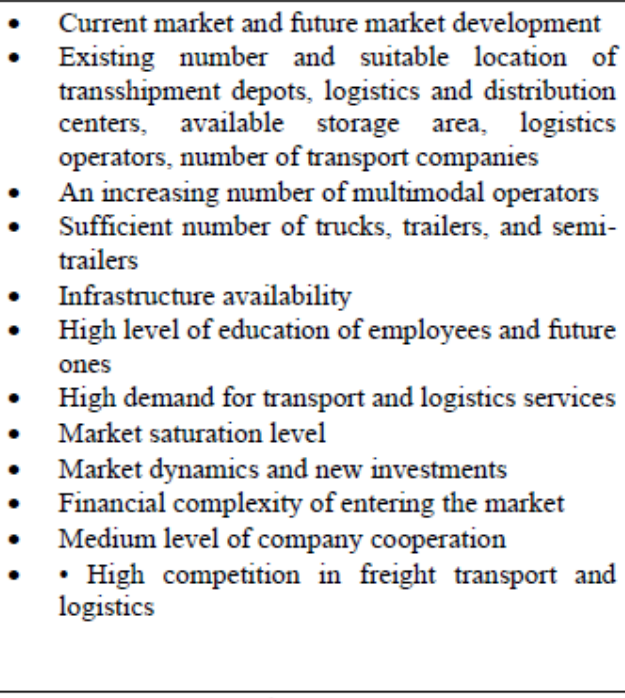 & $\begin{array}{l}\text { - } \\
\text { - } \\
\text { - } \text { Promoting greener transport modes due to the } \\
\text { Strategic transport position, new investors, state } \\
\text { investments, and subsidies } \\
\text { - Taxes and tolls - increase } \\
\text { - Stability of EU policy - security, duty-free union } \\
\text { - Intensification of cooperation between entities } \\
\text { - Transit through international corridors } \\
\text { - Taking environmental aspects into account in } \\
\text { - } \text { sustainable transport policy } \\
\text { Development of multimodal transport to reduce } \\
\text { transport costs } \\
\text { Support for the development of multimodal } \\
\text { transport from the EU } \\
\text { Development of transport infrastructure within } \\
\text { individual transport modes } \\
\text { Development of shipping containers and their } \\
\text { standardization } \\
\text { Development of new technologies }\end{array}$ \\
\hline Weaknesses & Threats \\
\hline $\begin{array}{l}\text { - Low number of employees } \\
\text { - } \text { - High employee turnover } \\
\text { - Low quality of roads, waterways, and railways } \\
\text { - Insufficient level of investment in the } \\
\text { development of freight transport by the state } \\
\text { - Support for financial institutions, government } \\
\text { institutions } \\
\text { - } \\
\text { - Highergency condition of some roads } \\
\text { - Higher price of alternative fuels } \\
\text { - Limited offer of means of transport } \\
\text { - Lack of joint European projects } \\
\text { - Small infrastructure condition check } \\
\text { - Different amounts of investment in different } \\
\text { - } \text { Absence of high-speed rail }\end{array}$ & $\begin{array}{l}\text { - Lack of employees } \\
\text { - High labor costs } \\
\text { - Financial risks associated with long-term } \\
\text { projects } \\
\text { - Lack of transparency of political influences } \\
\text { Obstruction of institutions in investments in } \\
\text { transport } \\
\text { - Roadblocks ecologists, landowners, strikes } \\
\text { Infrastructure problems such as poor quality, low } \\
\text { - Lapacity, construction delays, and infrastructure } \\
\text { - Legrades of financial projects in the national budget } \\
\text { - } \text { bureaucracy in terms of time } \\
\text { - Srowth in passenger transport } \\
\text { Slow rail transport }\end{array}$ \\
\hline
\end{tabular}

Fig. 2. SWOT analysis of the Multimodal transport in EU - Author 
The Czech Republic strives above all for the innovation of international transport in particular, which is only partially carried out here. The increased use would therefore mainly concern rail transport, to a lesser extent also water transport. This would reduce exhaust emissions, the largest production of which is road transport. If road transport cannot be replaced, either due to infrastructure or the type of goods transported, the use of other types of propulsion (hydrogen, electricity) is an alternative. [7] There are 13 currently used multimodal terminals in the Czech Republic. On four of them, it is possible to realize transshipment between three modes of transport, at other terminals, it is possible to tranship only between road and rail transport. The benefits of intermodal transportation development lie in the process of connecting all the operators and parties involved in the international trade between Southeast Asia and the EU countries. [8]

\section{Multimodal transport chain and its organization}

Transport is part of the logistics chain, which consists of activities of an administrative, legal and technological nature. In the case of the transport of products by multimodal transport, in which several modes of transport are interconnected, the organization and coordination of the whole transport process are considerably more complicated.

In normal transport, the chain works in such a way that the consignor, consignee, or trade organization enters into a transport contract with a specific carrier. The selected carrier will perform the transport using the means of transport for the given type of transport and the given type of product. In more complicated multimodal transports, another entity enters the process. This is a freight forwarder who concludes a contract with the sender. Its function is to mediate and coordinate all activities related to the transport - warehousing, customs procedures, concluding transport contracts with carriers, insurance. At the same time, he is responsible for the given transport to the sender according to the concluded contract. In the case of multimodal transport, there is a so-called multimodal transport operator (MTO), which ensures the implementation of the entire transport chain. They provide transport through their own or leased terminals and cooperate with foreign multimodal transport operators.

\section{Model case}

- The customer who is interested in the implementation of the transport will contact the forwarder (MTO) with a request for a price offer for transport. This is based on the address of loading and unloading, quantity, weight, and time conditions.

- After receiving the offers, a comparison and evaluation will take place. Confirms the selected order, concludes a transport contract. The forwarder hereby undertakes to transport the goods properly to the designated place for the ordering party, on time and with optimal conditions. The goods must be delivered undamaged and in unchanged quantity and quality.

- The carrier will provide a suitable transport unit, which must be manageable at both the consignee and the consignor and must be accessible to the consignor. Large ISO 1 deep-sea containers for deep-sea transport are available in larger multimodal transport terminals.

- The road carrier will take over this transport unit from the sender and transport it to the nearest agreed multimodal transport terminal. After loading, the combination goes to the nearest multimodal transport terminal, where the semitrailer or swap body is transferred to the railway car and the vehicle (tractor) leaves the terminal. It is very important to follow the departures of combined transport trains from the terminal so that it is still possible to ensure their transfer to the railway car of the respective train from the multimodal transport terminal. In case of non-compliance with the cut-off time in the terminal, the containers will be placed on the storage area of the multimodal transport terminal, where the containers are left until the departure of the next train. This storage service is charged, especially for longer periods.

- At the destination terminal, the road hauler or the transport operator contracts another road hauler to transport the goods to the consignee.

In the transport process, continuous information about any extraordinary event or change on the part of the sender, carrier, or final consignee is required. In the event of an emergency, it is necessary to immediately activate the relevant and pre-arranged emergency scenario. The final evaluation of the transport should always be performed. This can also be due to unplanned logistics costs, non-compliance with agreed parameters, or quality Databases with environmental performance data for transport chains should be developed. [9]

\section{Conclusion}

Interest in multimodal transport in the European Union is still growing. The use of multimodal transport will divide the transport into more transport modes. This situation then makes it possible to take advantage of their benefits and at the same time avoid some of the problems and risks associated with specific modes of transport. The shift of costs from the most frequently used road transport to multimodal transport is supported by the entire European Union. It committed itself to this in the document Concept of Freight Transport for the period 2017 to 2023 with a view to 2030. The expansion of multimodal transport is complicated by a number of obstacles that hinder the necessary and rapid development. 
The main reason is the critical emergency condition of the infrastructure in some regions, the existence of equipped transhipments, especially railways. These include, for example, narrow capacity bottlenecks on important main lines. This reduces the reliability and timeliness of train journeys to destination terminals. The solution is, for example, the construction of corporate terminals, which will enable the use of new transport solutions with universal cars and interchangeable superstructures. It is possible to use the financial support of the European Union for their construction. The development of transport in the EU is identified in the White Paper on Transport and in the strategic documents of individual member states. Transport is the basis of the European economy and society, and the mobility of goods and people is very important. It is important to increase traffic, promote mobility and at the same time aim to reduce emissions by up to $60 \%$. To this end, it is necessary in the future to create a new common pattern of transport, according to which transport will be realized by means of the most efficient fastening means or their interconnection.

The European Union for Transport Development must meet the following main requirements:

- increasing the energy efficiency of vehicles,

- optimization of multimodal logistics chains,

- greater involvement of road traffic management systems and information,

- financial support from public funds of the state and its investments in the development of road transport and infrastructure

- construction and modernization of multimodal terminals and logistics centers, as well as improving access to the use of EU funds in this area

- the creation of common European funds for multimodal transport to support the development of this transport system,

- favoring multimodal chain carriers

- $\quad$ support for multimodal concessions

Another EU transport target for 2050 is to shift $30 \%$ of road transport to 2030 and to $50 \%$ by 2050 . Rail or water transport will help to do this, which is an alternative in terms of cost and less negative effects on the environment. In particular, road traffic will be reduced and thus carbon monoxide emissions will be reduced. The issue of multimodal transport will continue to require increased attention and effective solutions in the future. Therefore, individual progress will be further monitored, and comparisons will be made between individual flights and countries. These will be further published as a continuation of the article assessing the fulfillment of the objectives, how the individual states have committed themselves in the future, and recommendations on which of the successes other states and communities should adopt and which, on the contrary, did not lead to the expected results.

\section{Acknowledgments}

This research was based on the support of the Internal Grant Agency of Tomas Bata University in Zlín, the IGA / FAI / 2021/002 project and the Institute of Safety Engineering, Faculty of Applied Informatics.

\section{References}

[1] https://ec.europa.eu/eurostat/data/database (2021) Accessed on: 2021-02-15

[2] Hanus, J. (2014). Comparison of individual modes of transport with regard to the impact on the environment. Universita Jan Perner. Pardubice

[3] Besta, P. (2021) Comparison of individual modes of transport. College logistics. ISBN 2021-03-28. Prerov, Czech republic

[4] https://www.sydos.cz/cs/rocenka-2020/rocenka/htm_cz/index.html (2021) Accessed on: 2009-08-13

[5] Tichy, M. (2006). Risk management: Analysis and management. ISBN 80-7179-415 Prague

[6] Management Mania, Risks, (2021). Accessed on: 2021-03-28.

[7] Ministry of transport of the Czech Republic. (2016) Freight concept for the period 2017-2023 with wiew to 2030. Accessed on: 2021-03-28.

[8] Bendekovic, J., Rogozar, Z., Naletina, D. (2014) Intermodal transport is brand of Croatia transport offer, Proceeding of DAAAM International Symposium, ISBN 978-3-90150998-8, Editor B. Katalinic, Published by DAAAM International, Vienna, Austria.

[9] Nicolae, F., Popa C., Beizaheda, H. \& Nistor, F. (2010) Enviromental performance assesment of multimodal transport system. Proceeding of DAAAM International Symposium, ISBN 978-3-901509-73-5. Editor B. Katalinic, Published by DAAAM International, Vienna, Austria. 